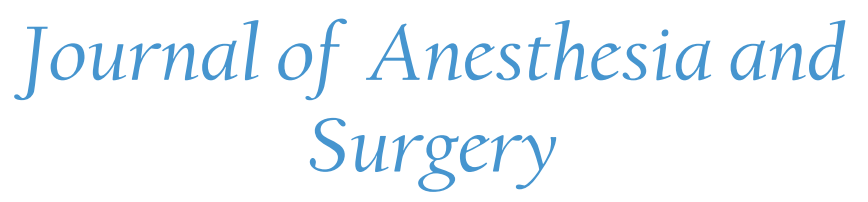

\title{
Comparative Study of Hernia Block with Bupivacaine Alone and Bupivacaine plus Dexamethasone as Adjuvant for Open Hernia Repair at Day Care Unit
}

\author{
Usha P.Patel ${ }^{1 *}$, Pritesh R. Patel ${ }^{2}$ \\ ${ }^{1}$ Consultant Anaesthetist, Shree raj hospital, Drive in road \& Bopal, Ex. Assistant professor AMCMET Medical College, Sheth \\ L.G. General Hospital Ahmedabad, Gujarat \\ ${ }^{2}$ Consultant surgeon, Shree Raj Hospital Drive in road and Bopal, Ahmedabad, Gujarat
}

*Corresponding author: Usha P. Patel, Consultant Anaesthetist, Shree raj hospital, Drive in road \& Bopal, Ex. Assistant professor AMCMET Medical College, Sheth L.G., General Hospital Ahmedabad, Gujarat; E-mail: drpiyushpujara@gmail.com; doctorushapatel@gmail.com

\begin{abstract}
Introduction: Continuous research were undertaken in past to see the effect of anesthetic agent with adjuvant agents to increase their effect. The addition of adjuvant substances as clonidine, Dexmedetomidine, tramadol, midazolam, opioids, adenosine, to the local anesthetic drugs in TAPB and their efficiency have been studied. Hence the aim of the present study was to check the effect of Bupivacaine alone and Bupivicaine plus Dexamethasone in hernia block.

Material \& Methods: The total of 60 patients with age range from 30 to 60 years was included in the study. All the 60 patients were divided in to two groups, with 30 patients in each group. Group 1 consisted of 30 patients were administered with $20 \mathrm{ml}$ of $0.5 \%$ bupivacaine in a TAP block performed at the same side of surgery to be performed. Group II consisted of 30 patients; were administered with $20 \mathrm{ml}$ of $0.5 \%$ bupivicaine with $2 \mathrm{ml}$ of dexamethasone in a TAP block performed at the same side of surgery.

Results: In the present study, the duration of analgesia was found to be significantly longer in the Group II when compared to Group I. VAS scores done 30 minutes after surgery were comparable between the 2 Groups. However the different was found to be statistically significant.

Conclusion: Appropriate pain treatment protocols to reduce postoperative morbidity, improve the results of the surgery and decrease hospital costs. Adequate postoperative pain relief is associated with positive long-term effects for patients such as; reduced postoperative cognitive changes, better quality of life and reduced risk of chronic or persistent postoperative pain. On reviewing the literature it was found that local anesthesia has more advantages compared to other kind of anaesthesia. A potential advantage of local anesthesia realized without any monitoring or additional drugs administered intravenously.
\end{abstract}

\section{Introduction}

Open Inguinal hernia is one of the most commonly performed surgical procedures in elderly. Treatment of this type of pathology is exclusively surgical and relies always on the contribution of local anaesthesia. This type of anaesthesia has significantly improved the treatment of inguinal hernia, which has significantly reduce the complications, recurrences, recovery time and can return to normal working activities ${ }^{[1,2]}$. Most of the surgery involves a tension free mesh repair for the hernia. Patches are sewn over the weakened area in the abdominal (belly) wall after the hernia is pushed back into place. The patch decreases the tension on the weakened belly wall, reducing the risk that a hernia will recur ${ }^{[3,4]}$.

The surgery of the hernia is performed under different anaesthetic techniques as described as general or regional anaesthe-

Copyrights: (C) 2017 Patel, U.P. This is an Open access article distributed under the terms of Creative Commons Attribution 4.0 International License.

Received date: May 7, 2017

Accepted date: September 11, 2017

Published date: September 13, 2017

Citation: Patel, U.P., Patel, P.R. Comparative Study of Hernia Block with Bupivacaine Alone and Bupivacaine plus Dexamethasone as Adjuvant for Open Hernia Repair at Day Care Unit. (2017) J Anesth Surg 4(2): 93- 96.

DOI: $10.15436 / 2377-1364.17 .079$

Keywords: Hernia Block; Bupivacaine; Dexamethasone; Open Hernia Repair 
sia, which is many time is associated with post operative severe pain. The amount is pain experienced is related to the somatic pain signal which is derived from abdominal wall. The anterior abdominal walls are supplied by sensory neurons which are derived from anterior rami of spinal nerves $\mathrm{T} 6$ to $\mathrm{L}^{[5,6]}$.

Post operative pain and swelling over the incison are the common complication encountered. Post operative pain leads to increase consumption of anesthetic agents, which increase the risk of adverse effect of anesthesia especially emesis, vomiting and respiratory depression; reduces the advantages of immediate surgery and increases the hospital stay ${ }^{[7]}$.

The transverse abdomen is plane block first described by Rafi in 2001 is a peripheral nerve block designed to anesthetize the nerves supplying the anterior abdominal wall (T6 to L1). The introduction of ultrasound has allowed providers to identify the appropriate tissue plane and perform this block with greater accuracy under direct visualization ${ }^{[8]}$. TAP block has also found clinical utility in procedures such as abdominal and inguinal hernia repair, radical prostatectomy, nephrectomy, and many different laparoscopic procedures in general. Very few contraindications exist to performing a TAP block. Absolute contraindications include infection at the site of injection, patient refusal or inability to cooperate, and allergy to local anesthetics.

Among all anaesthetic agents bupivacaine is used as a local anaesthetic and is available in sterile solution for injections via local infiltration and TAP block. However to increase the effect and to maintain longer duration of the anaesthetic pain continuous research in undertaken, so that patients comfort can be increased $^{[9]}$. Continuous research were undertaken in past to see the effect of anaesthetic agent with adjuvant agents to increase their effect. The addition of adjuvant substances as clonidine, Dexmedetomidine, tramadol, midazolam, opioids, adenosine, to the local anesthetic drugs in TAPB and their efficiency have been studied. Hence the aim of the present study was to check the effect of Bupivacaine alone and Bupivicaine plus Dexxamethasone in hernia block.

\section{Materials and Methods}

The present study was carried out the medical institute in Gujarat. Before conduction of the study, the ethical committee of the institute was informed and ethical clearance certificate was obtained. All the participating patients were informed prior to the conduction of the study and informed consent were signed by all the patients. Only those patients who signed the informed consent were included in the study. The total of 60 patients with age range from 30 to 60 years was included in the study.

All the 60 patients were divided in to two groups, with 30 patients in each group. Group 1 consisted of 30 patients were administered with $20 \mathrm{ml}$ of $0.5 \%$ bupivacaine in a TAP block performed at the same side of surgery to be performed. Group II consisted of 30 patients; were administered with $20 \mathrm{ml}$ of $0.5 \%$ bupivicaine with $2 \mathrm{ml}$ of dexamethasone in a TAP block performed at the same side of surgery.

Before the patients were undertaken for surgery, prior history were taken, clinical examinations of history recording was done. Routine lab test were completed and recorded. All the patients were prior informed about the study and also the TAP block procedure. All the patients were asked to fast for at least 6 hours before surgery. Patient was pre-medicated with injection midazolam $0.02 \mathrm{mg} / \mathrm{kg}$ body weight.

The needle was inserted perpendicular to the skin just above the highest point of iliac crest, in the posterior axillary line where a depression was felt. Needle was inserted slowly until a pop was felt- indicating the needle piercing the external oblique fascia. The needle was further advanced until a second pop was felt- indicating the needle piercing the internal oblique fascia and entering the transverses abdominal plane.

Before administration of the anesthetic agent, negative aspiration was checked to rule out the vascular involvement. After the confirmation of the negative aspiration $20 \mathrm{ml}$ of $0.5 \%$ bupivacaine as administered into TAP in group I where as in group II $20 \mathrm{ml}$ of $0.5 \%$ bupivicaine with $2 \mathrm{ml}$ of dexamethasone in a TAP block. Time taken for onset of sensory block is taken as the time gap between the end of injecting local anaesthetic to loss of sensation above the injected site and time for complete sensory and motor blockade (T10 - L1) was recorded. Post-operative readings were taken every $2^{\text {nd }}$ hourly, until the patient asked for first rescue analgesia. VAS (Visual analogue scale) score was also recorded at the time of rescue analgesia. All the patients were kept awake throughout the procedure. At the end of the study, following parameters were measured. For pain assessment, VAS scale was measures, Duration of analgesia, patient satisfaction and lastly any post operative complications.

Data were recorded and analysed with SPSS software. Qualitative data were described using number and percent. Distribution of qualitative data was done by Chi square test.

\section{Results}

Student t-test has been used to find the significance of study parameters on continuous scale between two Groups. Inter Group analysis on metric parameters. Chi-square test has been used to find the significance of study parameters on categorical scale between two or more Groups. A total of 60 patients were included in the study. All the patients were divided into two groups namely: Group I: 30 patients and Group II: 30 patients. Table 1 described the duration of analgesia in both the groups. In the present study, the duration of analgesia was found to be significantly longer in the Group II when compared to Group I $(\mathrm{p}<0.001)$.

Table 1: Duration of analgesia.

\begin{tabular}{|l|c|c|}
\hline Duration of analgesia (Hrs) & Group I n (\%) & Group II n (\%) \\
\hline $1-5 \mathrm{hrs}$ & 0 & 0 \\
\hline $6-10 \mathrm{hrs}$ & $22(73.3)$ & $4(13.3)$ \\
\hline $11-15 \mathrm{hrs}$ & $4(13.3)$ & $8(26.6)$ \\
\hline $16-20 \mathrm{hrs}$ & $4(13.3)$ & $12(40)$ \\
\hline$>20 \mathrm{hrs}$ & 0 & $6(20)$ \\
\hline Total & 30 & 30 \\
\hline
\end{tabular}

A total of 60 patients were recruited for the study. Age and gender were comparable in between the Groups. VAS scores done 30 minutes after surgery were comparable between the 2 Groups. However the different was found to be statistically significant. [Table 2]

In Table 3 we have evaluated complications of treatment. In the first group I six patients experienced nausea, six vomiting, one itching, and one infection. Instead in the group 
II, four patients experienced nausea, three vomiting, one itching and one infection. The difference between the two group was found to be statistically significant. In the Table 4 overall satisfaction by the patient is evaluated. It was assessed using a scale of five levels. In group I twenty patients said they have been absolutely satisfied, six very satisfied, two moderately satisfied, two satisfied and no one has been disappointed. In the second group, twenty-five patients have been absolutely satisfied, three have been very satisfied, two satisfied moderately satisfied, no one disappointed. The difference was found to be statistically significant with $\mathrm{p}<0.05$.

Table 2: VAS Score.

\begin{tabular}{|l|c|c|}
\hline VAS score & Group I n (\%) & Group II n (\%) \\
\hline $\mathbf{0}$ & $6(20)$ & $3(10)$ \\
\hline $\mathbf{1}$ & $6(20)$ & $8(26.6)$ \\
\hline $\mathbf{2}$ & $8(26.6)$ & $14(46.6)$ \\
\hline $\mathbf{3}$ & $10(33.33)$ & $5(16.6)$ \\
\hline Total & 30 & 30 \\
\hline
\end{tabular}

Table 3: Post-operative complications.

\begin{tabular}{|l|c|c|c|}
\hline Complications & Group I n (\%) & Group II n (\%) & \multirow{2}{*}{ P value } \\
\hline Nausea & $6(26.6)$ & $4(13.3)$ & \multirow{2}{*}{0.02} \\
\cline { 1 - 3 } Vomiting & $6(26.6)$ & $3(10)$ & \\
\cline { 1 - 3 } Infection & $1(3.3)$ & $1(3.3)$ & \\
\cline { 1 - 3 } Itching & $1(3.3)$ & $1(3.3)$ & \\
\hline
\end{tabular}

Table 4: Degree of patient's satisfaction.

\begin{tabular}{|l|c|c|c|}
\hline Patient's Satisfaction & Group I & Group II & \multirow{2}{*}{ P Value } \\
\hline Absolutely satisfied & $20(66.66)$ & $25(83 / 33)$ & \\
\cline { 1 - 3 } Very satisfied & $6(26.6)$ & $3(10)$ & \multirow{2}{*}{0.03} \\
\cline { 1 - 3 } Moderately satisfied & $2(6.6)$ & $2(6.6)$ & \\
\cline { 1 - 3 } Satisfied & $2(6.6)$ & 0 & \\
\cline { 1 - 3 } Disappointed & 0 & 0 & \\
\cline { 1 - 3 }
\end{tabular}

\section{Discussion}

Hernia is an abnormal protrusion of a viscus or part of it through a normal or abnormal opening in a cavity, usually the abdomen. They are most commonly seen in the groin; a minority are paraumbilical or incisional. In the groin, inguinal hernias are more common than femoral hernias ${ }^{[10,11]}$.

Inguinal hernia is one of the most common conditions met with in surgical practice. The male-female ratio is greater than $10: 1$. Life time prevalence is $25 \%$ in men and $2 \%$ in women. Two-thirds of inguinal hernias are indirect and nearly twothirds of recurrent herniae are direct ${ }^{[12]}$. Post-operative pain after inguinal hernia lead to the increased consumption of analgesics, delayed bowel function and increase the requirement for rescue analgesics which raises the risk of adverse effects especially respiratory depression, emesis and sedation, which can lead to increased duration of hospital stay and thereby reduce the advantages of fast-track surgery ${ }^{[13]}$.

Appropriate pain treatment protocols to reduce postoperative morbidity, improve the results of the surgery and decrease hospital costs. Adequate postoperative pain relief is associated with positive long-term effects for patients such as; reduced postoperative cognitive changes, better quality of life and reduced risk of chronic or persistent postoperative pain ${ }^{[1,15]}$. On reviewing the literature it was found that local anesthesia has more advantages compared to other kind of anaesthesia. A potential advantage of local anesthesia realized without any monitoring or additional drugs administered intravenously.

The aim of the present work is to evaluate the effect of pre-emptive dexamethasone added to bupivacaine on postoperative pain in patients, time of the first request for additional analgesia. Pain scores, post operative complications and patient satisfaction. The demographic data was matched between the two groups.

This study is the first to examine the effect of dexamethasone on plain bupivacaine for in patients with hernia. We observed that prolongation of block duration was 1.5 to 2 times when dexamethasone was added as an additive to plain bupivacaine. This block prolongation was also observed when dexamethasone was combined with mepivacaine. Similarly, K. C. Cummings $3^{\text {rd }}$ et al., also observed that, dexamethasone significantly prolonged the duration of ropivacaine and bupivacaine when used for the interscalene block. However, the existing literature supports the clinically important benefit we observed in our study.

Elderly patients with hernia are more prone to delirium because of pain and medications. Adequate analgesia not only prevents delirium but also, allows increased mobility and shorter hospital stay. Third point, postoperative complications. In group I, 20\% experienced symptoms such as nausea and / or vomiting, $5 \%$ itching, $2.5 \%$ infection. In group II, $15 \%$ noted nausea and / or vomiting, $5 \%$ itching, $2.5 \%$ infection. Group I shows a significantly higher number of complications, as already demonstrated by previous studies.

Fourth point, overall satisfaction, patients in group II have been absolutely satisfied for $60 \% 20 \%$ very satisfied. 10 $\%$ moderately satisfied, $10 \%$ satisfied and $0 \%$ disappointed. Instead patients in group II expressed $70 \%$ complete satisfaction, $20 \%$ have been very satisfied, $10 \%$ moderately satisfied, $10 \%$ satisfied and $0 \%$ disappointed. In neither of the two groups we have found any signs of toxicity by anesthetic agent.

\section{Conclusions}

Addition of dexamethasone to bupivacaine in patients receiving plain block guided for inguinal hernia repair result in, longer time till first opioids requirement, prolonged the duration of the block, less requirement for opioids, patients more satisfied and decreased the incidence of nausea and vomiting. 


\section{References}

1. Shah, A.A., Sinatra, R.S. Complications of Postoperative Pain and Pain Management. (2014) Complications in Surgery and Trauma Second Edition: CRC Press 375-392.

Pubmed $\mid$ Crossref $\mid$ Others

2. Bongard, F., Dubecz, S., Klein, S. Complications of therapeutic laparoscopy. (1994) Current problems in Surgery 31(11): 868-924.

Pubmed | Crossref | Others

3. Fitzgibbons, R.J., Giobbie-Hurder, A., Gibbs, J.O., et al. Watchful waiting vs repair of inguinal hernia in minimally symptomatic men: a randomized clinical trial. (2006) JAMA 295(3): 285-292.

Pubmed | Crossref $\mid$ Others

4. Jain, S.K., Stoker, D.L., Tanwar, R. Basic Surgical Skills and Techniques. (2013) JP Medical Ltd.

Pubmed $\mid$ Crossref $\mid$ Others

5. Weltz, C.R., Klein, S.M., Arbo, J.E., et al. Paravertebral block anesthesia for inguinal hernia repair. (2003) World journal of surgery 27: 425-429.

Pubmed | Crossref | Others

6. Simons, M., Aufenacker, T., Bay-Nielsen, M., et al. European Hernia Society guidelines on the treatment of inguinal hernia in adult patients. (2009) Hernia Springer

Pubmed | Crossref | Others

7. Marley, R.A., Swanson, J. Patient care after discharge from the ambulatory surgical center. (2001) Journal of PeriAnesthesia Nursing 16: 399-419.

Pubmed | Crossref | Others

8. Gupta, M., Goodson, R. Transverse Abdominal Plane Neurostimulation for Chronic Abdominal Pain: A Novel. (2014) Pain physician 17: E619-E22.

Pubmed | Crossref $\mid$ Others

9. Salinas, F.V., Liu, S.S., Mulroy, M.F. The effect of single-injection femoral nerve block versus continuous femoral nerve block after total knee arthroplasty on hospital length of stay and long-term functional recovery within an established clinical pathway. (2006) Anesthesia \& Analgesia 102(4): 1234-1239.

Pubmed | Crossref | Others

10. Aufenacker, T.J., de Lange, D.H., Burg, M.D., et al. Hernia surgery changes in the Amsterdam region 1994-2001: decrease in operations for recurrent hernia. (2005) Hernia 9(1): 46-50.

Pubmed | Crossref | Others

11. Alani, A.M. Management of asymptomatic inguinal hernias. (2008) University of Glasgow.

Pubmed $\mid$ Crossref $\mid$ Others

12. Fouad, H.A., Ahmed, A.S., Mohammed, Y., et al. EFFICACY OF PREEMPTIVE DEXAMETHASONE ADDED TO BUPIVACAINE IN ULTRASOUND GUIDED TRANSVERSUS ABDOMINUS PLAIN BLOCK FOR POSTOPERATIVE ANALGESIA AFTER INGUINAL HERNIORRAPHY.

Pubmed $\mid$ Crossref $\mid$ Others

13. Schell, D., Somal, J. Multimodal management of pain and postoperative nausea and vomiting (PONV) in ambulatory surgery. (2015) Practical Ambulatory Anesthesia 79.

Pubmed $\mid$ Crossref $\mid$ Others

14. Grass, J.A. The role of epidural anesthesia and analgesia in postoperative outcome. (2000) Anesthesiology Clinics of North America 18(2): 407-428.

Pubmed $\mid$ Crossref $\mid$ Others

15. Pyati, S., Gan, T.J. Perioperative pain management. (2007) CNS drugs 21: 185-211.

Pubmed | Crossref | Others

Ommega Online Publishers

Journal Title: Journal of Anesthesia and Surgery (JAS)

Journal Short Name: J Anesth Surg
Journal ISSN: 2377-1364

E-mail: anestheisa@ommegaonline.com

Website: www.ommegaonline.org 